\title{
Surface Coating of Cyclotetramethylenetetranitramine (HMX) Particles and Its Property Investigation
}

\author{
Guo Yan ${ }^{1}$, Shi Xiaobing ${ }^{2}$, Pang Weiqiang ${ }^{2,3,{ }^{*}, \text { Qin Zhao }{ }^{3}, \text { Xu Huixiang }}{ }^{2,3}$, Li Huan ${ }^{2}$ and \\ Fan Xuezhong ${ }^{2}$
}

${ }^{1}$ School of Computer Science, Northwestern Polytechnical University, Xi'an 710072

${ }^{2} X i$ 'an Modern Chemistry Research Institute, Xi'an 710065 China

${ }^{3}$ Science and Technology on Combustion and Explosion Laboratory, Xi'an 710065 China

\begin{abstract}
To improve the safety of cyclotetramethylenetetranitramine (HMX) particles, the polymer thermoplastic polyurethane elastomer (TPU) and nitrocellulose (NC) were introduced to coat HMX powder by water-solution suspension method and internal solution method, respectively. Scanning electron microscope (SEM) and X-ray photoelectron spectrometry (XPS) were employed to characterize the HMX samples and the role of NC and TPU in the coating processes were discussed. The impact sensitivity, friction sensitivity, and the thermal decomposition of coated HMX particles were investigated, and compared to the unprocessed ones. The results indicate that both TPU and NC can improve the wetting ability of the coating materials on HMX surface and reinforce the connection between HMX and the coating materials. The impact sensitivity and friction sensitivity of HMX samples decrease obviously after they have been surface coated; the drop height $\left(H_{50}\right)$ is increased from $35.24 \mathrm{~cm}$ to $50.08 \mathrm{~cm}$, and the friction probability is reduced from $93.2 \%$ to $58.3 \%$. The activation energy $\left(E_{a}\right)$ and the self-ignition temperature increase by $10.46 \mathrm{KJ} \cdot \mathrm{mol}^{-1}$ and 1.8 , respectively.
\end{abstract}

Keyword: Material chemistry, Surface coating, Thermoplastic polyurethane elastomer, HMX, Safety properties, Thermal decomposition.

\section{INTRODUCTION}

Nitromine explosives (such as RDX and HMX) have been widely used in propellants and gun propellants due to their high-energy performance, good stability, and low cost. However, they are sensitive to impact and friction stimuli. To lower the sensitivity toward mechanical stimuli, one way is to control the crystal morphology producing mostly spherical particles, while the control process is a little bit difficult for researchers [1-3]. Also another porpular technology, surface coating, was developed to reduce the sensitivity of explosive crystals in recenct years [4]. Up to now, many materials have been used to coat nitromine explosives, such as wax, graphite, stearic acid, and high polymers [5-8]. However, the explosion performance of coated samples has a tendency to decrease because of the introduction of non-energetic materials. In order to solve this problem, the insensitive explosives, i.e., 2,4,6-trinitrotoluede (TNT) [9], 3-nitro1,2,4-triazole-5- one (NTO) [10], and 1,3,5-triamino2,4,6-trinitrobenzene (TATB) [11] were introduced to coat them. Also, a kind of double-deck composite explosive was prepared via coating RDX with TNT and a plasticizer [12], their experimental results indicated

*Address correspondence to this author at the Xi'an Modern Chemistry Research Institute, Xi'an 710065 China; Tel: +8602988291765;

E-mail : nwpu_pwq@163.com that the mechanical sensitivity was reduced and the energy did not decrease after coating. Thus, several energetic materials were chosen and used to coat $\mathrm{HMX}$ and RDX, Nitrocellulose (NC) is one of the important energetic components in solid propellants and explosives, which can improve the mechanical characteristics of isocyanate-cured propellants. ZHANG Wei [13] prepared the RDX particles coated with NC, it was found that the RDX coated with NC (NC@RDX) particles could swell in nitrate ester plasticizers with relatively low swelling rate compared with NC added directly in the plasticizers and NC@RDX can improve the mechanical characteristics of the propellant with maximum tensile strength, elongation at maximum tensile strength, and elastic modules in the temperature range form -40 to $+50{ }^{\circ} \mathrm{C}$. In this work, the polymer thermoplastic polyurethane elastomer (TPU) and nitrocellulose (NC) were introduced to coat HMX to form core-shell structure (TPU@HMX and NC@HMX) and to reinforce the binding force between core and shell. The specific synthesis craft was explored and the safety properties of coated samples were estimated.

\section{EXPERIMENTAL}

\subsection{Materials}

HMX, NC, and TPU are provided by Xi'an Modern Chemistry Research Institute of China; Ethanol and 
ethyl acetate are purchased from Shanghai Chemical Ltd. of China.

\subsection{Equipment and Characterization}

The profiles of HMX and its coated samples are characterized by JSM-5800 scanning electronic microscope (SEM) made in Japan. The element contents on the sample surface were analyzed by PH15400 X-ray electron spectrometer made by American PE Co.

Impact sensitivity and friction sensitivity of samples are measured and evaluated with National Army Standard of China. Impact sensitivity is surveyed by the drop hammer apparatus. The experimental conditions are as follows: drop hammer weight, $2 \mathrm{~kg}$; sample mass, $(30 \pm 1) \mathrm{mg}$. Friction sensitivity is tested by pendulum friction apparatus made by Xi'an Modern Chemistry Research Institute of China. The experimental conditions are as follows: pendulum weight, $1.5 \mathrm{~kg}$; swaying angle, $66^{\circ}$, sample mass, $(20 \pm$ 1) $\mathrm{mg}$.

The thermal decomposition experiments are carried out with TA instrument made in USA. The conditions of DSC are as follows: sample mass, less than $2.00 \mathrm{mg}$; the heating rate is $5{ }^{\circ} \mathrm{C}, 10{ }^{\circ} \mathrm{C}, 15{ }^{\circ} \mathrm{C}$ and $20 \mathrm{~K} \cdot \mathrm{min}^{-1}$, respectively; $\mathrm{N}_{2}$ atmosphere. The conditions of TGDTG experiments are as follows: heating rate, 10 $\mathrm{K} \cdot \mathrm{min}^{-1}$; sample mass, less than $3.00 \mathrm{mg}$.

\subsection{Preparation of Samples}

HMX is coated by water-solution suspension method and the internal solution method, respectively. The main processes are as follows: Firstly, TPU was dissolved in a mixture of ethanol and ethyl acetate, and the HMX powder is slurred in water at about $80{ }^{\circ} \mathrm{C}$. Secondly, the solution of coating materials (TPU) is introduced into the slurry slowly. This process is carried out under the condition of stirring sufficiently, until the solvents are removed completely, the temperature is reduced to $50{ }^{\circ} \mathrm{C}$. After filtration, rinsing, and evaporation in vacuum at $40{ }^{\circ} \mathrm{C}$ the coated samples with TPU are fabricated. In addition, about $120 \mathrm{~mL}$ water was added into a kettle with impeller inside, and $9 \mathrm{~g} \mathrm{HMX}$ powder (12.7 um) and $1 \mathrm{~g} \mathrm{NC}$ (N: 11.99 wt.-\% and $M_{\mathrm{n}}: 83 \times 10^{3} \mathrm{~g} \cdot \mathrm{mol}^{-1}$ with degree of polymerization $\mathrm{n}: 150)$ were mixed in the kettle for $10 \mathrm{~min}$, then ethyl acetate was added for $30 \mathrm{~min}$, the kettle was vacuumed at $0.094 \mathrm{MPa}$ for $15 \mathrm{~min}$ to evaporate the solvent, finally the mixture was released and intensively washed for five times with water at $60{ }^{\circ} \mathrm{C}$, dried the sediment of HMX particles at $50{ }^{\circ} \mathrm{C}$ for seven days, thus, HMX coated with NC particles were obtained.

\section{RESULTS AND DISCUSSION}

\subsection{SEM Characterization and Granularity Distribution of HMX Particles}

Unprocessed and coated HMX samples are characterized by SEM, the particle size and size distribution of HMX particles uncoated and coated were determined. The results are shown in Figures 1, Figures 2 and Table 1, respectively.

As can be seen in Figure 1(a), there are a lot of irregular particles for the unprocessed HMX particles, and the particle distributions are not disperse evenly. Figure 1(b) shows that the surface coated HMX particles with TPU disperse evenly and their surfaces are quite smooth, most of the coated HMX particles display as spherical or close to spherical shapes, also, there are many small particles are attached to the surface of HMX. Figure 1(c) indicate that the shape of HMX particles are improved greatly, and the particles distributions are more widespread than those of unprocessed particles. Figure 1(b) and (c) indicate that
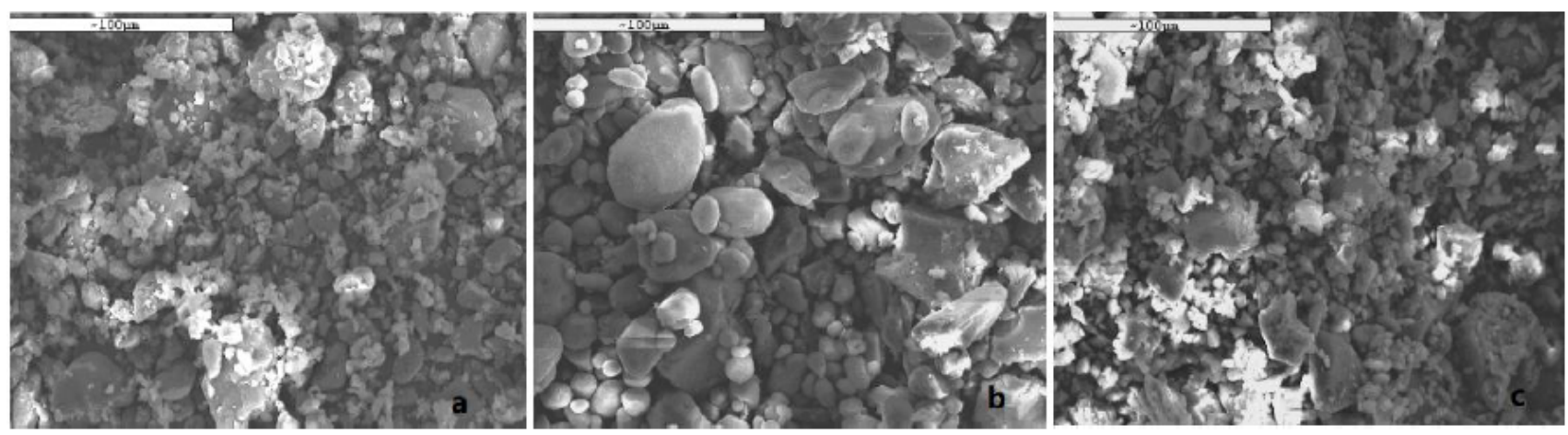

Figure 1: The SEM photograph of unprocessed and coated HMX samples: (a) unprocessed HMX sample; (b) HMX samples coated with 5 wt-\% TPU; (c) HMX samples coated with 5 wt.-\% NC. 

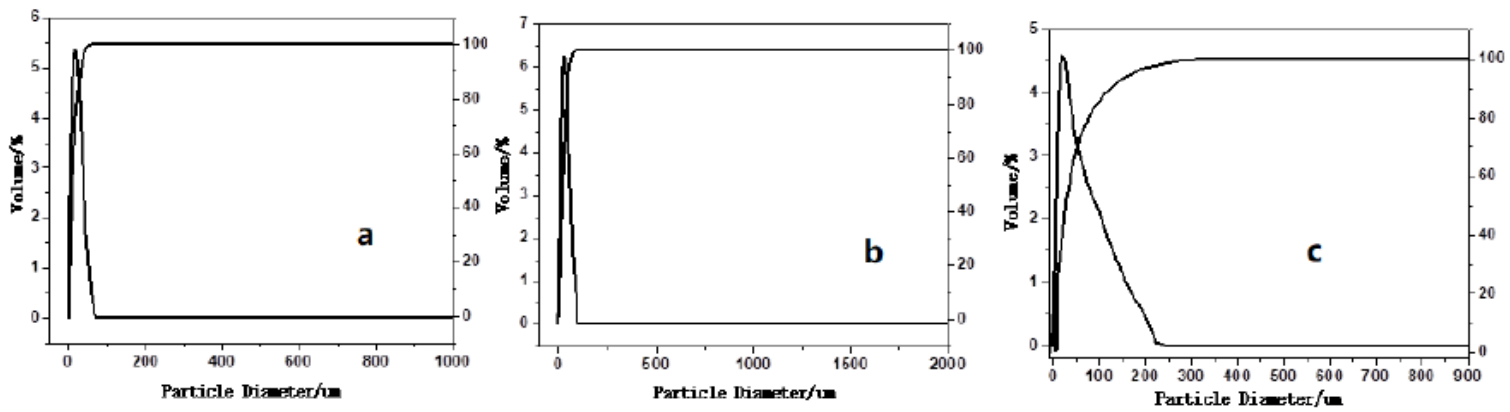

Figure 2: Granularity distribution of unprocessed and coated HMX samples: (a) unprocessed HMX sample; (b) HMX samples coated with 5 wt-\% TPU; (c) HMX sample coated with 5 wt.-\% NC.

Table 1: Determination of HMX Samples with Different Particle Sizes and Size Distribution

\begin{tabular}{|c|c|c|c|c|}
\hline Items & unit & a & b & c \\
\hline .12 & $\mu \mathrm{m}$ & 2.653 & 5.648 & 4.321 \\
\hline$d_{50}$ & $\mu \mathrm{m}$ & 12.755 & 22.986 & 20.475 \\
\hline$d_{90}$ & $\mu \mathrm{m}$ & 34.097 & 54.367 & 81.578 \\
\hline Span & - & 2.465 & 2.120 & 3.773 \\
\hline Surface area mean & $\mu \mathrm{m}$ & 5.327 & 8.601 & 7.458 \\
\hline Vol. weight mean & $\mu \mathrm{m}$ & 15.927 & 26.965 & 33.069 \\
\hline Specific surface area & $m^{2} \cdot g^{-1}$ & 1.130 & 0.698 & 0.805 \\
\hline
\end{tabular}

$d_{10}$ : particle diameter corresponding to $10 \%$ of the cumulative undersize distribution, $\mu \mathrm{m} ; d_{50}$ : median particle diameter, $\mu \mathrm{m} ; d_{90}$ : particle diameter corresponding to $90 \%$ of the cumulative undersize distribution, $\mu \mathrm{m}$; Span $=\left(d_{90}-d_{10}\right) / d_{50}$; and specific surface area refers to the particle size distribution determined by Malvein Mastersizer.

an obvious coarse layer is continuously distributed over the surface of each particle.

It can be seen from the results in Table 1 that the median particle diameter $\left(d_{50}\right)$ increase from $12.755 \mu \mathrm{m}$ to $22.986 \mu \mathrm{m}$, whereas, the specific surface area decrease from $1.13 \mathrm{~m}^{2} \cdot \mathrm{g}^{-1}$ to $0.698 \mathrm{~m}^{2} \cdot \mathrm{g}^{-1}$, respectively. The results indicate that the coated HMX particle sizes are larger than those of uncoated ones.

\subsection{XPS Analysis of HMX Particles}

The coating degree, $R$, a parameter indicating the coating effect, is estimated according to the mass fraction of $N$ [14]. The larger the value of $R$ is, the better the coating effect is. Where $N_{\text {HMX }}$, and $N_{\text {sam. }}$ are the mass fraction of $N$ of the unprocessed and coated samples, respectively. Whose values are listed in Table 2; $N_{\mathrm{C}}$ is the mass fraction of $N$ of coating material calculated by their molecular formula. $R$ is the coating degree.

$N_{\mathrm{HMX}}(1-R)+N_{\mathrm{C}} R=N_{\text {sam. }}$

The surface elementary as fraction of samples is also obtained by XPS, and the surface elementary content of unprocessed and coated HMX samples is characterized by XPS. The results are shown in Table 2. The XPS results show that by surface coating,

Table 2: XPS Results of HMX Samples

\begin{tabular}{|c|c|c|c|c|c|}
\hline \multirow{2}{*}{ Samples } & \multicolumn{2}{|c|}{ Mass Fraction of Elements in the Sample Surface/\% } & \multirow{2}{*}{ Coating Degree $(R) / \%$} \\
\cline { 2 - 5 } & NC & Cls & N1s & O1s & 0 \\
\hline \hline Unprocessed HMX & 0 & 50.13 & 15.34 & 28.30 & 43.87 \\
\hline Coated HMX with TPU & - & 58.24 & 8.43 & 32.65 & 38.52 \\
\hline Coated HMX with NC & 12.42 & - & 12.16 & - & \multirow{2}{*}{0} \\
\hline
\end{tabular}


the mass fraction of $N$ decreases from $15.34 \%$ to 8.43 $\%$, which is because the $N$ content in the NC and TPU is lower than that of in the HMX. Moreover, the coating degree $(R)$ is calculated as $43.87 \%$ and $38.52 \%$, suggesting that the coating layer is compact.

\subsection{Mechanical Sensitivity Analysis}

The mechanical sensitivity properties as one of the most important aspects, the impact and friction sensitivity of unprocessed and coated HMX particles are tested and the results are listed in Table 3 . The results of the friction sensitivity test are expressed by the explosion probability $(P)$ and the impact sensitivity by the drop height $\left(H_{50}\right)$.

From Table 3, it is found that the greater $P$ is, the higher the friction sensitivity is, while the higher $H_{50}$ is, the lower the impact sensitivity is. $H_{50}$ and $P$ of unprocessed HMX are $35.24 \mathrm{~cm}$ and $93.2 \%$, respectively, whereas the impact and friction sensitivity of HMX samples coated with different content of NC and TPU decrease. Moreover, they have a tendency to reduce with the increase in coated materials, which has been found by many researchers. They deemed that $\mathrm{NC}$ and TPU materials play a buffer and lubrication role when external forces were acted on the coated HMX sample, therefore leading to a reduction in the probability of formation of hot spots $[15,16]$. With the increase content of TPU, both the impact and friction sensitivity reach the lowest and $H_{50}$ and $P$ are $50.08 \mathrm{~cm}$ and $58.3 \%$, respectively. These sensitivity results are almost the same to the mechanical sensitivity of samples coated with $5.0 w_{t-}-\% \mathrm{NC}$.

\subsection{Thermal Decomposition Tests}

The thermal stability of explosives is defined as the ability to keep the chemical properties from transforming under the thermal action. It can be expressed by the peak temperature $\left(T_{p}\right)$ and its selfignition temperature $\left(T_{\mathrm{b}}\right)$, which is evaluated by Eq.(2). The values of $E_{a}$ and $A$ are worked out by Kissinger's method (Eq. (3))[17, 18] with DSC data listed in Table 3.

$\frac{E}{R T_{\mathrm{b}}^{2}}\left(T_{b}-T_{e}\right)=1$

$\ln \frac{\beta_{i}}{T_{e i}^{2}}=\ln \frac{A R}{E}-\frac{E}{R T_{e i}}$

where $T_{\mathrm{b}}$ is the self-ignition temperature, $\mathrm{K} ; E_{\mathrm{a}}$ is the activation energy, $\mathrm{J} \cdot \mathrm{mol}^{-1} ; \beta_{\mathrm{i}}$ is the heating rate, $\mathrm{K} \cdot \mathrm{min}^{-}$ ${ }^{1} ; T_{\mathrm{ei}}$ is onset temperature of the decomposition at $\beta_{\mathrm{i}}, K$; $A$ is the pre-exponential factor; and $R$ is the gas constant, $8.314 \mathrm{~J} \cdot \mathrm{mol}^{-1} \cdot \mathrm{K}^{-1}$.

The results in Table $\mathbf{4}$ show that compared with that of unprocessed $\mathrm{HMX}$, the activation energy $\left(E_{a}\right)$ and

Table 3: Mechanical Sensitivity of Unprocessed and Coated HMX with Different Content of TPU and NC

\begin{tabular}{|c|c|c|c|c|}
\hline \multirow{2}{*}{ Samples } & \multicolumn{2}{|c|}{ Content/\% } & Impact Sensitivity/cm & Friction Sensitivity/\% \\
\cline { 2 - 5 } & TPU & NC & $\boldsymbol{H}_{\mathbf{5 0}}$ & $\boldsymbol{P}$ \\
\hline \hline 0 & 0 & 0 & 35.24 & 63.2 \\
\hline 1 & 2.5 & 0 & 46.23 & 58.3 \\
\hline 2 & 5.0 & 0 & 50.08 & 81.2 \\
\hline 3 & 0.5 & 0.5 & 39.67 & 77.1 \\
\hline 4 & 0 & 2.5 & 44.71 & 61.6 \\
\hline 5 & 0 & 5.0 & 48.33 & \\
\hline
\end{tabular}

Table 4: The DSC Data and Calculated Results

\begin{tabular}{|c|c|c|c|c|c|c|c|c|c|c|c|c|}
\hline Thermal Data & \multicolumn{4}{|c|}{ Unprocessed HMX a } & \multicolumn{4}{|c|}{ b } & \multicolumn{4}{|c|}{ c } \\
\hline$\beta_{i} / \mathrm{K} \cdot \mathrm{min}^{-1}$ & 5 & 10 & 15 & 20 & 5 & 10 & 15 & 20 & 5 & 10 & 15 & 20 \\
\hline \multicolumn{13}{|l|}{$T_{\mathrm{e} /} / \mathrm{K}$} \\
\hline$T_{\mathrm{p}} / \mathrm{K}$ & 554.55 & 558.35 & 562.15 & 564.07 & & & & 564.99 & & & & 564.55 \\
\hline$E_{\mathrm{a}} / \mathrm{J} \cdot \mathrm{mol}^{-1}$ & \multicolumn{4}{|c|}{215.64} & \multicolumn{4}{|c|}{228.73} & \multicolumn{4}{|c|}{232.91} \\
\hline
\end{tabular}


the self-ignition temperature $\left(T_{\mathrm{b}}\right)$ of coated samples $\mathrm{b}$ and $c$ increase, respectively. Consequently, the thermal stability of coated samples improves slightly.

Based on the performance analysis of coated HMX particles, the mechanical sensitivity of coated HMX were reduced significantly, which is beneficial to their applications in solid propellants and explosives.

\section{CONCLUSIONS}

(1) Surface coated HMX particles could be prepared by the water-solution suspension method and the internal solution method, respectively.

(2) Polymer material TPU can improve the wetting ability of the coating material and reinforce the connection between HMX and the coating material NC significantly, which is successfully coated on the surface of HMX.

(3) The impact and friction sensitivities of coated HMX decrease significantly. After coating with 5.0 wt.$\%$ content of TPU, the drop height $\left(H_{50}\right)$ increases by $42.1 \%$, and the friction probability $(P)$ reduces by $59.9 \%$.

(4) The thermal stability of coated samples improves slightly according to the unprocessed ones.

\section{REFERENCES}

[1] Pang WQ, Deluca LT, Gromov A, Cumming A. (2020) Innovative Energetic Materials: Properties, Combustion and Application. Springer. https://doi.org/10.1007/978-981-15-4831-4

[2] Schmid H. Coating of Explosives, J. Hazard. Mater. 1986; 13: 89. https://doi.org/10.1016/0304-3894(86)80010-3

[3] Trache D, Klapötke TM, Maiz L. et al. (2017) Recent advances in new oxidizers for solid rocket propulsion. Green Chemistry, 20 https://doi.org/10.1039/C7GC01928A

[4] Johansen $\mathrm{OH}$, Kristiansen JD, Giesoe R, Berg A, Halvorsen $\mathrm{T}$, Smith K, Nevstad GO. RDX and HMX with Reduced Sensitivity towards Shock Initiation-RS-RDX and RS-HMX,
Propellants, Explos., Pyrotech. 2008; 33: 20. https://doi.org/10.1002/prep.200800203

[5] Kroer H, Teipel U. Crystallization of Insensitive HMX Propellants, Explos., Pyrotech. 2008; 33: 44 https://doi.org/10.1002/prep.200800207

[6] Doherty RM, Watt DS. Relationship Between RDX Properties and Sensitivity, Propellants, Explos. Pyrotech. 2008; 33:4. https://doi.org/10.1002/prep.200800201

[7] Svension L, Nyqvist JO, Westlin L. Crystallization of HMX from g-butyrolactone, J. Hazard. Mater. 1986; 13: 103. https://doi.org/10.1016/0304-3894(86)80011-5

[8] Dreerman E, Birnholz A, Gill M. Influence of Nitrocellulose on Mechanical and Ballistic Behavior of XLDB Propellant, 36th Int. Annual Conference of ICT \& 32nd International Pyrotechnics Seminar, Karlsruhe, Germany, June 28-July 1,2005, p156/1

[9] Larry C. Warren, Minimum Signature Isocyanate Cured Propellants Containing Bismuth Compounds as Ballistic Modifiers, US Patent 6168677B1. 2001, Huntsville, AL. The United States of America as represented by the Secretary of the Army, USA.

[10] Everette M. Piece, Smokeless Propellant Compositions Having Polyester or Polybutadiene Binder System Crosslinked with Nitrocellulose. SU Patent 4216039, 1980. Somerville. AL. The United States of America as represented by the Secretary of the Army, USA.

[11] Anderson E. Robinson, Jr., Crosslinked Double Base Propellant Binders. US Patent 423364,1980. Destin, FL. Hercules Incorporated, USA.

[12] RL. Simpson, PA. Urtiew, DL. Ornellas, Cl-20 Performance Exceeds that of HMX and its Sensitivity is Moderate, Propellants, Explos. Pyrotech 1997; 22: 249. https://doi.org/10.1002/prep.19970220502

[13] ZHANG Wei, FAN Xuezhong, WEI Hongjian, et al. Application of Nitramines Coated with Nitrocellulose in Minimum Signature Isocyanate-Cured Propellants. Propellants, Explosives, Pyrotechnics, 2008; 33(4): 279-285. https://doi.org/10.1002/prep.200800220

[14] Kim KJ, Kim HS, Agglomeration of NTO on the Surface of HMX Particles inWater-NMP Solvent, Cryst. Res. Technol. 2008; 43: 87. https://doi.org/10.1002/crat.200710946

[15] Sun J, Huang H, Zhang Y, Zheng MX, Liu JL. In Situ Coating of TATB on HMX, Chin. J. Energ. Mater. 2006; 14: 330 (Chinese)

[16] Hu RZ, Sun LX, Fu XY, Liang YJ, Wu SX, Wang Y. Thermal Stability of Some Furazano-Fused Cyclic Compounds, Thermochim. Acta 1990; 171: 31. https://doi.org/10.1016/0040-6031(90)87003-U

[17] Liu ZR. (2008) Thermal Analysis of Energetic Materials. Beijing: National Defence Industry Press.

[18] Hu RZ, Gao SL, Zhao FQ. (2008) Thermal Analysis Kinetics. Beijing: Science Press.

Received on 10-07-2021

DOI: https://doi.org/10.31875/2410-4701.2021.08.9

(c) 2021 Yan et al.; Zeal Press.

This is an open access article licensed under the terms of the Creative Commons Attribution Non-Commercial License (http://creativecommons.org/licenses/by-nc/3.0/) which permits unrestricted, non-commercial use, distribution and reproduction in any medium, provided the work is properly cited. 